\title{
From John Yudkin to Jamie Oliver: A Short but Sweet History on the War against Sugar
}

\author{
Rachel Meach
}

In 2016, an anti-sugar campaign headed by celebrity chef Jamie Oliver was launched in the United Kingdom. Dubbed a 'crusade against sugar', Oliver's documentary Sugar Rush examined Britain's penchant for sweetness, exposing the health implications of excessive consumption and calling on the British government to tax sugary drinks in order to reduce obesity and diet-related diseases. ${ }^{1}$ In the midst of the furore that ensued, the National Obesity Forum (NOF) and the Public Health Collaboration (PHC) published a report, which demanded a major overhaul of official dietary guidelines. The report condemned the dietary doctrine of 'low fat', which had dominated official dietary guidelines in the United Kingdom since 1983, alleging the advice was based on 'flawed science' which had failed to curb rates of obesity and type 2 diabetes. ${ }^{2}$ Their call intensified the debate even further; while members of the PHC described lowfat guidelines as 'the biggest mistake in modern medical history', others warned that reversing the current guidelines may prove disastrous for public health. ${ }^{3}$

Central in this debate was the concern that by buying into the 'low-fat' ideology, people unknowingly increased their consumption of refined sugar as a result. As the food industry had replaced fat with sugar in many of its 'low-fat' products, nutritionists and the public alike began to question whether it was not fat after all, but sugar, fuelling the epidemic of chronic disease. ${ }^{4}$ Consequently, a war of nutritional ideology between fat and sugar, first waged in the 1950s, has re-emerged in an attempt to solve the enigma of diet-related disease.

The idea that sugar consumption could be potentially detrimental to health is not a new one. Towards the end of the 1950s, heightened fears of coronary heart disease fuelled a search for the dietary components responsible for the dramatic rise in cardiovascular mortality and other diet-related diseases. During the surge in nutrition research that followed, nutritionists polarized into two distinct groups. One group followed American nutritionist Ancel Keys and believed that dietary fat was to blame; the other concurred with the views of British nutritionist John Yudkin that carbohydrates, primarily refined sugar, was responsible. In the decades that saw heart diseases accelerate, sugar consumption rose in parallel, increasing sevenfold since $1900 .{ }^{5}$ Nevertheless, as evident in the dominance of 'low-fat' dietary recommendations 
that followed, Keys and his critique of fat won the debate and Yudkin's warnings about sugar lay dormant until recent years. This chapter explores the development of the diet-heart debate, analysing how ideas about diet and disease were disseminated to the public and the role they played in shaping official dietary guidelines and nutritional discourses in both Britain and the United States. The chapter begins with a historical overview of the link between sugar and disease before moving on to analyse the dietheart debate in more detail, focusing in particular on the publications of John Yudkin, the late British nutritionist, renowned for his 'prophecy' on the dangers of sugar. ${ }^{6}$ This section examines a range of Yudkin's works but specifically addresses his series of diet and weight loss books published during the 1950s to 1980s which sought to promote a low-carbohydrate diet before moving on to assess the impact Yudkin's warning had on twentieth-century dietary guidelines. The following chapter thus sheds light on the social, political and cultural factors that influence our notions of the ideal diet, reappraising the views of John Yudkin; it attempts to understand why his warnings about sugar were ultimately dismissed.

\section{Sugar's place at the table}

Sugar first made its way to England in the twelfth century and what little quantities arrived were typically reserved for the wealthy. Over the next five centuries, its availability increased slowly until around 1650 when the modernization and expansion of refineries allowed for greater production. According to historian Sidney Mintz, it was here that 'sugar began to change from a luxury and rarity to a commonplace necessity." Mass production and cheap labour lowered the price of sugar and it quickly found its place as a cheap source of energy within the diets of the working class. As a commodity only afforded by the rich, sugar was held in high esteem and its whiteness was seen to symbolize its purity, healthfulness and superiority over other sweeteners. ${ }^{8}$ However, as the price of sugar declined, and thus became widely consumed, ideas about sugar and its nutritional status were challenged.

Both historians, the medical professionals and epidemiologists alike maintain that the link between sugar consumption and chronic disease has corresponded with its development and increased presence in Western diets. Denis Parson Burkitt, the late surgeon renowned for his work on cancer and nutrition, remarked of the association between refined carbohydrate and disease that the 'fear that sugar may be injurious is as old as the written history of this sweet food.' Burkitt traced concerns surrounding sugar's nutritional value to India around $100 \mathrm{AD}$ when soon after the cultivation and importation of sugar cane from New Guinea, Charake Samhita ascribed both obesity and diabetes to this 'new article of diet. ${ }^{10}$ In the twentieth century, American investigators Emerson and Larimore (1924), having traced the reported rise in diabetic mortality in New York since 1866, ascribed their findings to changes in dietary habits, especially the rise in sugar consumption. Emerson and Larimore were the first to draw a definite correlation between the influence of social and environmental factors such as diet and the incidental rise of diabetes. ${ }^{11}$ Similarly in Britain, Stocks (1944), 
having studied the increase in diabetic mortality in England and Wales from 1861 to 1942, drew attention to the marked decline in diabetic mortality during the two world wars; this he believed was due to wartime rationing and reduced consumption of sugar. These findings, along with those of Himsworth (1949) were reassessed further by British surgeon Thomas Cleave in his book The Saccharine Disease (1974). A keen purveyor of the damaging health consequences of sugar consumption, Cleave drew a convincing link between the decline in sugar consumption during both world wars and the corresponding decline in diabetes mortality and the overconsumption of refined carbohydrates, notably sugar and flour, and the increase in many prevalent chronic diseases. Yet, despite this periodic connection between sugar consumption and disease, no other figure generated such controversy over sugar as the late British nutritionist John Yudkin. In a series of publications written during the 1950s to 1980s, Yudkin maintained that a host of chronic conditions, from diabetes, obesity and heart disease, to asthma, dermatitis and Crohn's disease, could be attributed to high consumption of sucrose. At the height of the diet-heart debate, Yudkin argued against the nutritional consensus of the time, stating that it was not fat, but sugar that was fuelling the post-war rise in cardiovascular mortality and many other chronic diseases.

\section{A war of nutritional ideology}

The emergence of the diet-heart debate at the end of the 1950s has been well documented. ${ }^{12}$ Yet among these accounts, consideration of the context in which the debate emerged has often been overlooked. Beginning in the 1950s, as the manufactured-food industry expanded, refined sugar had found its place as a crucial ingredient in a range of new foods and was vital in creating the image, particularly in the United States, of a consumer paradise with an abundance of ready-made, convenience foods. Yet, as sugar was being added to an increasing range of foods, rates of diabetes, obesity and heart disease were quietly escalating. As a MetLife study published in the New York Times in 1951 revealed, body fat had become America's 'primary public health problem. ${ }^{13}$ This anxiety regarding the relationship between diet and disease was heightened further in 1952 when the US president Eisenhower suffered a heart attack, an event which thrust the issue into the public domain. By the end of the 1960s, a war of nutritional ideology was in full swing, symbolized by a polarized debate between two eminent nutrition scientists.

In 1958, nutrition scientist Ancel Keys launched his Seven Countries Study, a major survey of the potential risk factors of cardiovascular disease. Keys asserted that fat was to blame for the rise in heart disease and only a diet low in fat would lower cholesterol and reverse the intensifying trend fast becoming prevalent across most of the Western world. ${ }^{14}$ Around the same time, British nutritionist John Yudkin found that sugar too appeared to correlate with heart disease in several countries and thus put forth his contending hypothesis that high sugar consumption was a key cause of heart disease. Initially, Yudkin seemed more agreeable to the idea that both fat 
and sugar were somehow implicated as mutually confounding variables, present in equally high levels in the diets of those he had observed. Writing in the Lancet in 1957 Yudkin claimed,

A consideration of some of the more readily available data on the incidence of coronary deaths and on food consumption makes it difficult to support any theory which supposes a single or major dietary cause of coronary thrombosis. ${ }^{15}$

Unlike Yudkin, Keys was unwavering in his belief that the escalation of heart disease was being fuelled by a single nutrient: fat. Agitated by this, Yudkin took to the Lancet to accuse Keys and his colleagues of using 'awkward facts' and 'cherry-picking only the data which supported their view.'. ${ }^{16}$

Despite his initial reluctance to support the idea of a single nutritional cause of heart disease, evident here in 1957, by the 1970s with the publication of the controversial (and later banned) Pure, White and Deadly, Yudkin too had subscribed to the idea of a single dietary cause of disease. Accordingly, Yudkin became persistent in his belief that a whole host of conditions, ranging from obesity, heart disease, cancer and diabetes to hyperactivity, eczema and arthritis, could all be traced back to sugar. ${ }^{17}$ Absent in much of the literature on the diet-heart debate is a consideration of why fat and sugar could not both be feasible as mutual dietary explanations. The possible explanations for this are both personal, reflecting the professional ambitions of individual nutrition scientists, and political, shaped by changes in the formation of official dietary guidelines and the increasing influence of the food industry and government in their formation. Gyorgy Scrinis concept of 'nutritionism' is particularly useful for understanding the latter. According to Scrinis, beginning in the 1960s, there was an increasing tendency towards a reductive understanding of nutrients in which foods became distinguished as either 'good' or 'bad'. This Scrinis argues signalled the emergence of a new nutritional era, one which became wholly obsessed with fat and focusing attention on single nutrients rather than address the role of food production techniques, additives or the metabolic interaction of different nutrients. ${ }^{18}$ Scrinis maintains that the narrow focus on fat, and later the different types of fat, served to focus the attention of the public and nutrition experts on the presence or absence of fat in foods, rather than on the processing techniques and other ingredients (i.e. refined sugar) used in production. ${ }^{19}$ Within this context, whereby it became fashionable to differentiate between 'good' and bad' foods and focus upon single nutrient explanations of disease, overall attention unquestionably focused on fat. Correspondingly, the food industry, heavily influenced by the powerful sugar lobby, fuelled this significantly by translating the findings of Keys et al. into an enormous array of low-fat products. ${ }^{20}$

The tendency to focus on single nutrients thus reflected the wider context in which the diet-heart debate emerged, particularly changes occurring within the field of nutrition as the change in the language of dietary advice seen above. However, this explanation alone is insufficient to explain why one dietary theory (fat) should dominate and rival theories such as Yudkin's attracted only limited support. Both sugar and saturated fat were associated with the risk of heart disease, yet Keys and Yudkin's 
hypotheses were situated as competing single-nutrient explanations. ${ }^{21}$ The possibility that both fat and sugar were mutually responsible for the rise in chronic disease was never seriously entertained, evident in the very public dismissal of Yudkin's ideas by most nutrition experts at the time and the deriding of his career by his contemporaries. ${ }^{22}$ Thus, in addition to considering changes within nutrition and the wider context at the time of the debate, it is worthwhile to likewise consider Yudkin's particular impact on the debate - his professional ambitions and how he disseminated his ideas about sugar to the wider public.

The narrative of Yudkin's career is fascinating and provides a unique perspective of the diet-health debate so often overlooked. Yudkin began his research career towards the end of the 1930s, primarily interested in the effects of vitamins and vitamin deficiency in the diet upon health. However, alongside this research, Yudkin had greater ambitions. In an anonymous letter published in the Times in 1942, Yudkin called for a nationwide 'Nutrition Council' which would be responsible for setting nutritional goals and recommendations for the entire population. ${ }^{23}$ Unnerved by the frank dismissal of this proposal, Yudkin persisted in his career in nutrition, becoming chair of physiology at Queen Elizabeth College, establishing a nutrition department and the first taught degree in nutrition in Britain. Yudkin's early academic publications from the 1940s to mid-1950s demonstrate a wide range of interests in nutrition, from vitamin deficiencies and nutrition quality to the psychology of food choice. Yet, by the 1960s, as the diet-heart debate intensified and attracted widespread publicity, Yudkin's interests narrowed, concentrating on the relationship between diet and the related conditions of obesity and heart disease, in particular connecting these with the consumption of sugar. ${ }^{24}$

The progression of Yudkin's career and the response to his ideas offers a window into the development of nutrition, in particular how nutritional debates can become caught up in corresponding cultural notions in an attempt to disseminate ideas regarding diet to the general public. An analysis of Yudkin's publications throughout his career demonstrates this to be the case, particularly reflecting popular ideas about gender and body weight. As his interest in the relationship between sugar and obesity augmented, Yudkin disseminated his warning against sugar widely in medical journals and newspapers but also, as discussed below, through a series of diet and weight loss books. In existing histories of the diet-heart debate, scholars have overlooked Yudkin's publications for a lay audience, choosing to focus on his scientific publications and academic papers instead. I argue here that Yudkin's diet and weight loss books are a crucial source for the historian that shed new light on the debate between dietary fat and sugar, elucidating why Yudkin's ideas were ultimately dismissed for decades and only revisited in recent years.

\section{Sugar, slimming and the 'expert'}

In 1958, Yudkin attended the scientific meeting of the British Medical Association (BMA) in Birmingham. Following a panel on obesity and exercise, Yudkin proposed that the BMA establish a panel of 'experts' to inspect slimming products, with which he 
claimed the public were being 'bombarded'. ${ }^{25}$ Referring to advertisements for slimming products in the British Medical Journal, Yudkin held,

I think we really ought not to have these advertisements in our journal. I should like to see the association setting up some sort of panel of people who know something about this and who would look at the products with which the public is being bombarded daily, and give some sort of seal to those which fulfil the wellrecognised criteria of respectable slimming preparations. ${ }^{26}$

Meanwhile, the same year, and precisely a year after first publishing his critique of sugar in the Lancet, Yudkin entered into the diet industry himself, publishing his first book, This Slimming Business, in an attempt to disseminate his ideas to the wider public. The book proved to be a bestseller and brought Yudkin's attack on sugar and 'yo-yo dieting' to national prominence. ${ }^{27}$ As the title of the book suggests, Yudkin's intention here was to branch out from scientific publications and reach a lay audience by tapping into the market of the expanding diet industry. Selling 200,000 copies in Britain alone, This Slimming Business was deemed a success and thus encouraged Yudkin to undertake further research into public attitudes towards health and nutrition. ${ }^{28}$ In 1963, along with his colleagues at Queen Elizabeth College, London, Yudkin published the study 'Knowledge of Nutrition amongst Housewives in a London Suburb. ${ }^{29}$ In the study, housewives were provided with questionnaires and asked to answer a list of true or false statements relating to diet, revealing Yudkin's growing interest in the diet industry, in particular women's thoughts on slimming. In the study of London housewives, Yudkin notes,

The housewives were asked what foods they would recommend to be cut out of the diet by a person who wanted to slim. It is interesting to see the high importance attached to foods containing carbohydrate, and the relatively low importance attached to foods rich in fats. ${ }^{30}$

Women's views on the foods to target are reflected in a number of questions; for example, when asked, 'If a friend wanted to slim what foods would you suggest they cut out of their diet?', the women ranked potatoes first, followed by bread and sugar while ranking fats firmly at the bottom. ${ }^{31}$ While the study highlights the disparity between the anti-carbohydrate sentiments of British housewives and Key's low-fat ideology, perhaps the most interesting aspect is Yudkin's evident agenda in gathering popular ideas about slimming and weight loss. One of the most apparent themes in all of Yudkin's diet books published thereafter is the association between adopting this type of diet and 'a slim figure. ${ }^{32}$ Reflecting the context in which he was writing, when women, housewives in particular, were considered to represent the 'feminine ideal', it can be argued then that Yudkin began to focus his nutritional agenda on the appearance, rather than health of women, connecting his ideals of a low-sugar diet with the archetypal slim figure. 
A year later Yudkin published his second diet book, The Complete Slimmer, later renamed Lose Weight, Feel Great for publication in the United States. Now positioning himself as the 'slimming expert', it became clear that appearance had become the primary benefit of a low-sugar diet, with improved health featuring merely as an additional bonus. Yudkin explains,

The more you really understand and accept the logic of what I say, the more easily you will be able to accept the advice I give you. And the benefits are much more than simply a good figure. You may well achieve a degree of health that you may have forgot was possible. ${ }^{33}$

Clarifying his intended audience, Yudkin continues,

Thirty of forty years ago, few people seemed to be worrying about whether they were too fat. Since that time, more and more people have been doing so. Mostly, these are young women whose excessive body shapes do not look the best in the current fashions. Of course, women's fashions change in what, to a man, seems an extraordinary and unpredictable way. But excessive bosoms, excessive hips, and an intermediate anatomy of similar dimensions, have been unpopular now for as long as women have discarded the many frills that were once considered feminine attire. Since that time, there has also been the cult of the seaside and sunbathing - the era of barest maximum. Women in fashion have, then, increasingly found it desirable to avoid inordinate curves and shapes and proturbances, which do not look well in the more revealing garments to which they have taken. ${ }^{34}$

A recurring message which appears in all of Yudkin's publications for popular audiences is that a low-carbohydrate diet is not only a means to good health, but is also essential to achieve and maintain a slim figure. It is clear that Yudkin, tapping into popular culture and advertising, viewed women as aspiring to emulate 'slim trim figures', or as he states in Lose Weight, Feel Great, 'being in fashion should not be confined to models. ${ }^{35}$ While Yudkin's interest in overweight and chronic disease undoubtedly stemmed from health concerns of consuming too many refined carbohydrates, the language used to communicate this idea to the public exploited cultural concerns regarding body weight and body image. Promoting what he describes as the aesthetic benefits of weight loss, Yudkin states, 'Let me hasten to say that I think the aesthetic incentive to avoiding overweight is commendable and quite important. ${ }^{36}$ In The Slimmer's Cookbook (1961), The A to Z of Slimming (1977) and his later Eat Well, Slim Well (1982), it can be seen, particularly from the front cover and illustrations inside the book, that women were the prime target audience of his nutritional agenda.

In conjunction with his diet books, Yudkin continued to publish widely in medical and scientific journals, challenging Key's fat hypothesis and decrying its growing popularity among nutrition scientists, the public and the food industry. Writing in the Lancet in 1964, Yudkin disparaged Key's 'Seven Countries Study', maintaining that heart disease could likewise be linked with high levels of sugar 
consumption. ${ }^{37}$ In his own study of thirty-four countries, Yudkin had found the national consumption levels of fat and sugar to be almost exactly the same, thus leading him to conclude that it was as likely that sugar was responsible. Yudkin's article was met with great interest as a number of responses in the Lancet elucidate. One particular response came from an English physician, who, curious about Yudkin's links between sugar and heart disease, had carried out his own research into men and women's consumptions habits, yet remained unconvinced. The response pointed out that while women consumed more sugar and sweet foods than men, heart disease appeared to be a 'distinctly male disease. ${ }^{38}$ The physician further added,

Professor Yudkin invites us to cut our sugar intake drastically, since 'we think it likely that we are dealing with a primary causal relationship between sugar intake and arterial disease. Elsewhere in the same paper he treats this assumption as only as only a hypothesis at present. In other words, sugar - historically, the latest addition to the list of our nutrients - has become the newest fashionable villain of the affluent society. A difficulty arises however. Were there - as Professor Yudkin suggests - a causal relation between sugar intake and I.H.D, one would expect the highest prevalence of this disease among those who consume the biggest amounts of sugar, sweets, biscuits, chocolate, ice cream, and puddings. Tentative observations seem to contradict this. I am far from claiming scientific accuracy for a small poll which I carried out among my patients with coronary-artery disease, at local confectioners, and also by asking waiters about the dessert orders of customers of a few humbles snack-bars and West-End restaurants. But one thing emerged. Young adult women and the 'upper-middle-aged' women constitute the overwhelming majority of sweet buyers, and they do not hesitate to ask for a pastry or pudding as dessert instead of 'men's cheeses'. I questioned the healthy wives of my patients with I.H.D as to their husband's consumption of sugar, and it was not conspicuously higher than their own. As is well known, there is a distinct sex difference in the prevalence of I.H.D in favour of the female. Do oestrogens suppress the hypothetical action of sugar, and, if so, in what way? ${ }^{39}$

This response to Yudkin's premise highlights the peculiar way in which concerns about the relationship between diet and disease had emerged due to the increase of mortality from heart disease, which as this letter highlights, in both the United States and Britain was a distinctly male disease, particularly common among older, white, affluent men. Yet, the dietary advice produced in response to the diet-heart debate, as discussed above, targeted not this cohort of men, however, but rather young women.

Despite this peculiarity, a growing diet industry ensured Yudkin's diet and weight loss books sold well. According to historian Harvey Levenstein, Yudkin's 'fame, along with his quick wit and engaging personality' ensured wide coverage of his ideas and despite attempts by those who supported Keys to deride him in the media, he successfully sued for referring to his work as 'science fiction. ${ }^{40}$ Ultimately, however, Yudkin's personality was not enough to secure his popularity and professional status. Those who supported Keys used their influence with research-granting agencies to 
drain him of funding and by 1970 Yudkin found himself pushed into retirement from his professorship, leaving him unsalaried in a backroom office.

Yudkin could not be supressed, however, and during his retirement wrote his final indictment of sugar, the seminal Pure, White and Deadly, published in 1971. At the end of his career Yudkin found both himself and his theory marginalized and derided; yet, he remained resolute in his ideas:

With many examples in mind of how information can be distorted or withheld, it becomes even more evident that people should not be left entirely to themselves to decide what they should or should not eat. Sooner or later, I feel, it will be necessary to introduce legislation that by some means or other prevents people from consuming so much sugar, and especially prevents parents, relatives and friends from ruining the health of babies and children. ${ }^{41}$

By the 1970s then, despite decades spent producing books targeting individual dieters, Yudkin believed the threat posed by sugar was not only more 'imminent and deadly', but that changing consumption habits could no longer be left to the individual and warranted state intervention.

Yudkin's work published at the height of the diet-heart debate thus demonstrate the development of Yudkin's career and the professionalization of the field of nutrition in addition to revealing much about the cultural context in which he was writing. That Yudkin, a renowned scientist, chose to enter the weight-loss industry to disseminate his ideas about sugar reveals the power of the diet industry and culture of slimming throughout the 1960s to 1980s. Despite the fact that the debate had arisen out of concerns about heart disease, which seemed to occur mainly in men, by the 1960s onwards it was women who had become the main targets of dietary advice on either side of the debate. According to Joan Brumberg, one explanation behind this can be found in the rapid change during this period in dieting and bodily ideals; 'After a brief flirtation with full-breasted, curvaceous female figures in the politically conservative post-war recovery of the 1950s, our collective taste returned to an ideal of extreme thinness and an androgynous, if not childlike figure'; as a result, she argues, our cultural tolerance for body fat diminished and women became the target of 'experts' to strive for a lean body. ${ }^{42}$

How conscious Yudkin was in his decision to tailor his advice towards women is uncertain. La Berge asserts how a century-long preference for slim bodies and losing weight using low-calorie diets was well entrenched as the diet-heart debate arose. Slimming and weight reduction, she argues, was a widespread social and cultural phenomenon among women from as early as the nineteenth century, waxing and waning in response to changing social, cultural, economic and political conditions. ${ }^{43}$ Thus, in both Britain and the United States, the diet-heart debate emerged within a context in which a diet culture was already firmly entrenched, of which the incentive had long been both aesthetic and medical. ${ }^{44}$

Yudkin's books sold well initially, and despite lacking the nutritional consensus of his colleagues, as the debate gathered momentum several key developments unfolded which seemed to add weight to his case. For the first time, nutritionists began to 
distinguish among different types of sugar along nutritional grounds. Until the 1960s, white and brown sugar, honey, syrup and molasses had been treated as a discrete category; however, in the late 1960s both nutritionists and non-experts alike began to rank these in a hierarchical order positioning white refined sugar, once known for its purity and healthfulness, firmly at the bottom..$^{45}$ Additionally, the American counterculture provided a weighty critique of the American diet, questioning the healthfulness of the food supply and drawing attention to the over use of artificial additives, both chemical and 'natural' such as sugar, in modern foods. ${ }^{46}$ By the $1970 \mathrm{~s}$ then, fears over 'hidden sugars' had mounted and the idea that additives could even be linked to childhood disorders like hyperactivity, an idea popularized by allergist Benjamin F. Feingold, gave increasing cause for concern. ${ }^{47}$

\section{Dietary goals and guidelines}

In 1973, the US Senate Select Committee on Nutrition and Human Needs was established to focus attention on the 'overnourished' and what to do about the rising rates of chronic disease. The committee spent the next 4 years looking into aspects of the American diet that had been linked to the leading killer diseases and concluded that too much fat, sugar, cholesterol, salt and alcohol were linked to cancer, cardiovascular disease, diabetes, coronary heart disease and cirrhosis of the liver. While both fat and sugar were listed as contributing to these diseases, the panel's final set of dietary goals, issued in December 1977, 'Dietary Goals for the United States', also referred to as the McGovern Report, manifested these findings into low-fat, highcarbohydrate recommendations.$^{48}$ In addition to warning the public about obesity, the guidelines advocated increasing carbohydrate consumption to 55 to 60 per cent of total daily intake while reducing fat from 40 to 30 per cent. ${ }^{49}$ Not only did the new recommendations apply to the general population, but also to those with chronic, diet-related disease such as diabetes. In breaking with decades of low-carbohydrate recommendations for diabetes, the American Diabetic Association (ADA), Canadian Diabetic Association (CDA) and the British Diabetic Association (BDA), in line with the changes made following the McGovern Report, increased the carbohydrate allowance for diabetics. Moving towards a diet similar to that of the general population, diabetics were now recommended to consume a high-carbohydrate diet. The BDA's 'Dietary Recommendations' for the 1980s stated,

The traditional view that restriction of carbohydrate is an essential part of the dietary management of diabetics can no longer be regarded as correct. Provided that the energy content of the prescribed diet does not exceed individual requirement, the proportion of energy consumed as carbohydrate is immaterial to diabetic control. ${ }^{50}$

Accordingly, the new guidelines for diabetics recommended a maximum of 35 per cent of dietary energy from fat and 55 per cent from carbohydrate, representing a 
significant reversal from former guidelines and years of research on nutrition and diets for diabetics. ${ }^{51}$

The publication of Dietary Goals reflected the federal government's official support of the low-fat approach. While the guidelines recommended that fat, sugar, salt and alcohol all be consumed less, it was the reduction of fat in particular which was emphasized continuously thereafter. Between 1978 and 1979, the American Society of Clinical Nutritionists, the American Heart Association and the National Cancer Institute all fell in line and produced their own low-fat recommendations and by 1980 a scientific consensus was emerging which promoted a low-fat diet as the appropriate diet not only as a preventable measure for those at risk of heart disease and cancer, but the entire population. ${ }^{52}$

\section{The saccharine saga}

While it appeared that Yudkin's warning about sugar had failed to achieve the same level of recognition as Keys's warning about fat, one subsequent event suggests that on some level, his ideas about sugar took hold. The debate surrounding the banning of artificial sweeteners, particularly cyclamate and saccharin, and the protest against the ban, suggests that there was substantial demand for a low-sugar alternative. In 1977, the same year as the McGovern Report had been published and low-fat became the dominant nutritional consensus, contention arose over the use of artificial sweeteners in foods following the results of a study in 1970 by the Canadian government which found saccharin as a potential cause of bladder cancer in rats. ${ }^{53}$ In response to the study, the FDA considered labelling saccharin as a drug, making it only obtainable in pharmacies. This suggestion was met with considerable protest from food manufacturers, consumers and lobbyists alike. ${ }^{54}$ The diabetic community in particular, both patients and their diabetic associations, while naturally wary, disapproved of the suggestion which would ultimately mean a diet completely devoid of the sweetness they had become accustomed to with the availability of special diabetic foods (see Figures 7.1 and 7.2). The ADA commented on the FDA's decision, warning that the unavailability of sugar substitutes could have 'very grave' effects for the 10 million Americans with diabetes, 'making it more difficult for these individuals to control their condition by dietary means. ${ }^{55}$

In 1977, the New York Times reported how the FDA's 2-day public hearings into its proposal to limit the use of saccharin were met with 'a mass outpouring of protest' as 'eight witnesses representing organisations of diabetics testified that the FDA proposal would undermine the efforts of 10 million diabetic Americans to stick to their sugarfree diets. ${ }^{56}$ With mounting pressure from the public, diabetic associations and lobbyists, coupled with the fact cyclamate had already been banned the decade prior and there were no 'no-sugar' alternatives, the FDA eventually reversed its decision, settling on warning labels on food packaging instead. Ultimately then this event suggests that while Yudkin's concerns about sugar may have failed to manifest as the dominant recommendation within nutritional advice, he nevertheless influenced the 


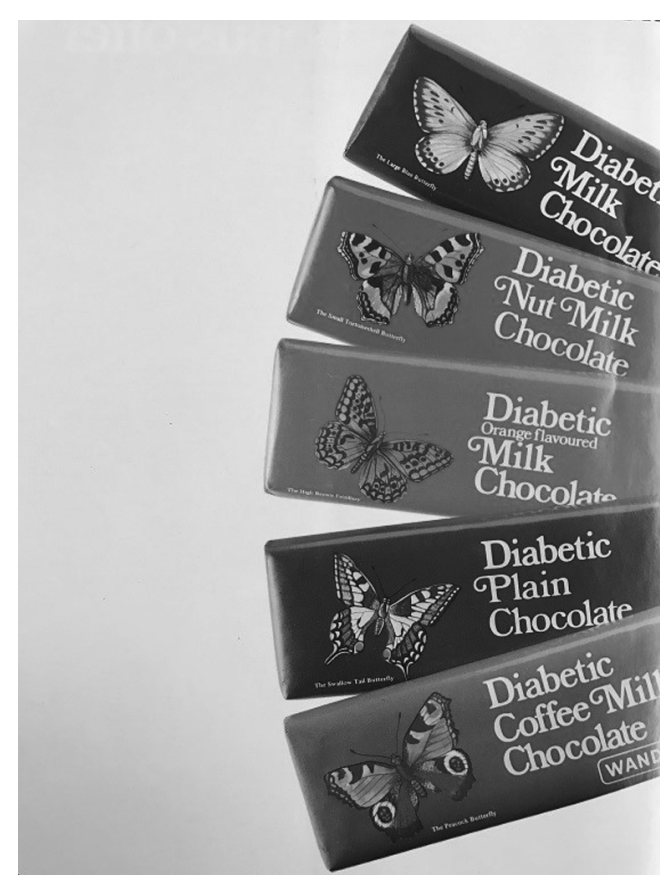

Figure 7.1 'Wander's Diabetic Chocolate'. Advertisement featured in supplement of the Chemist and Druggist (1979). Courtesy of the Wellcome Library, London

public's ideas about sugar consumption, in particular its association with obesity and henceforth the reluctance to give up artificial sweeteners as a substitute to its sweetness.

\section{Conclusion}

By examining the publications of the late British nutritionist John Yudkin, both his academic publications and those produced for a lay audience, this chapter has considered how mid-century warnings about sugar were disseminated to the public, how these were shaped by the wider social and cultural context and the impact of these upon the diet-heart debate as it unfolded in Britain and the United States. Amidst a rapidly changing food environment and expanding food industry that increasingly used sugar in food production, alarming rates of coronary heart disease and obesity spurred nutritionists, the media and the public to consider the connection between diet and disease and the role of single nutritional components in fuelling the emerging epidemic.

In subscribing to the trend which emerged in the 1960s of explaining the epidemic rise of chronic disease in a reductive, single-nutrient manner, Yudkin, through the use of diet books, sought to generate greater interest in his nutritional advice about sugar by appealing to women's health concerns, primarily that of being overweight. While 


\section{Cyclamate-free Diet De Luxe THE}
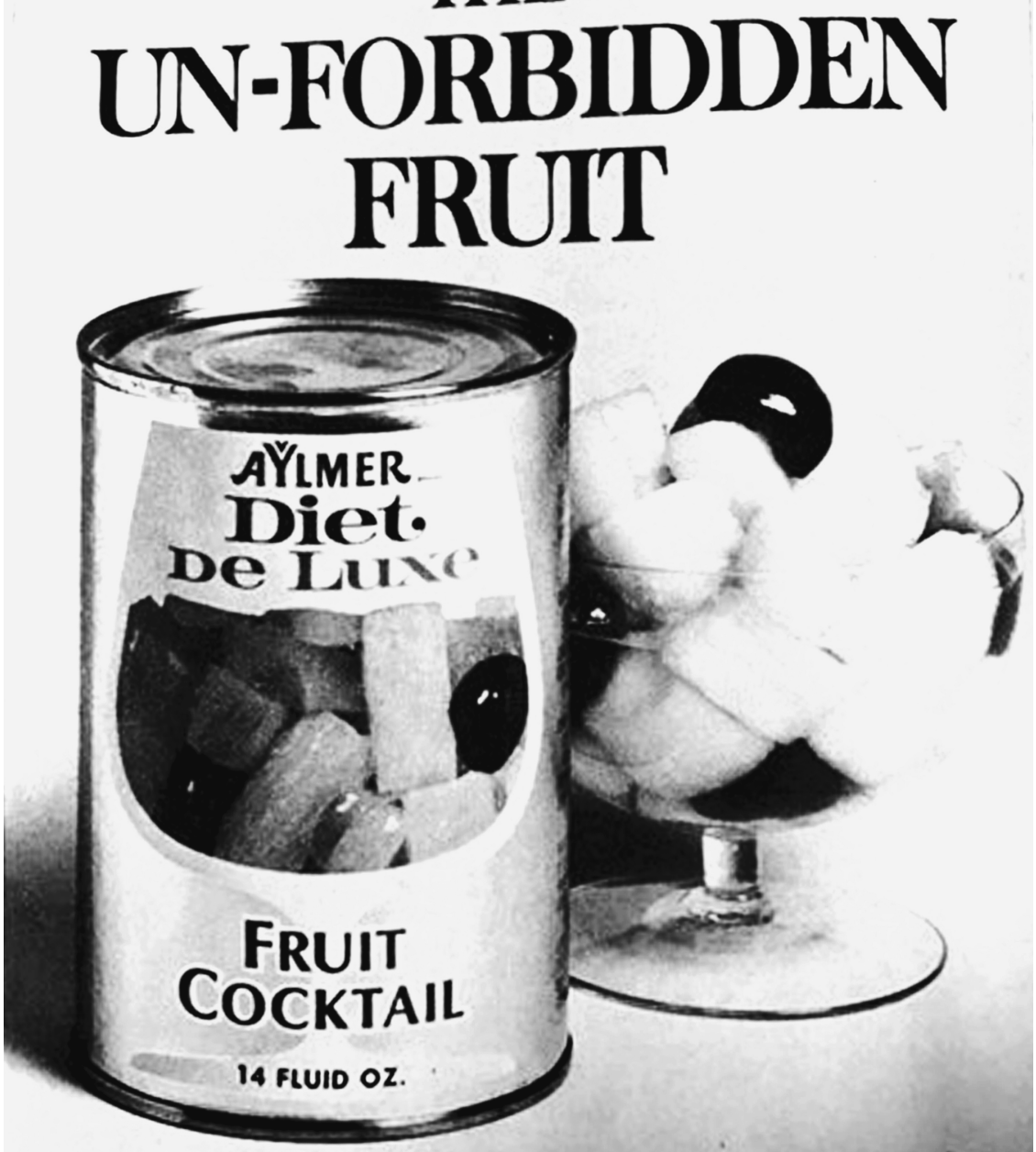

Figure 7.2 'Diet de Luxe Fruit Cocktail'. Advertisement featured in quarterly newsletter of the Canadian Diabetic Association, Vol. 20, No. 1 (1979). Courtesy of the Joslin Archive, Joslin Diabetes Centre, Boston, MA 
the main objective of his books was undoubtedly to disseminate his beliefs concerning the link between sugar and disease, he did so while simultaneously endorsing the cultural ideal of the slim body to his readership. Left derided at the end of his career, Yudkin's warnings ultimately fell on deaf ears. However, what can be assumed by his publications is his recognition of women as a prime target audience as he sought out professional merit. This was not because they were more susceptible to heart disease, but rather, because of their presumed penchant for sweetness.

The latest war against sugar, led by public figures such as Robert Lustig in the United States and celebrity figures like Jamie Oliver in Britain, has witnessed a resurgence of interest of Yudkin's otherwise dormant ideas. Reprinted in 2012, Pure, White and Deadly has been hailed a 'prophecy' which foretold the consequences of our increasing consumption of sugar long before the scientific evidence was available. While this has drawn due attention to the growing amount of sugar in our modern diet, these new debates have tended towards the same narrow focus on the ideological war between Keys and Yudkin, or fat or sugar, rather than the production and processing of foods, the interaction of combinations of different nutrients or overconsumption of food generally. Recent research suggests that both Yudkin and Keys could have been right that neither sugar or fat alone can lead to heart disease but a combination of them together as 'sweet fat' in packaged foods. Nevertheless, a narrow preoccupation with single nutrients has avoided, or at least stalled, research investigating this in a more systematic manner.

Ultimately, that Yudkin chose to disseminate his ideas about nutrition and health in this way not only reveals much about social and cultural atmosphere in which he was writing, ideas pertaining to gender, health and expert knowledge, but also demonstrates that by the 1960s, nutrition scientists were now finding themselves transcending the realms of the research laboratory and the scientific journal and becoming popular and commercial figures. By entering into the diet industry and with significant coverage in both the popular press and public health media, the debate penetrated the public sphere and influenced ideas about diet and health much greater than any previous nutritional debate. Accordingly, this attention afforded the debate much greater scope to influence official dietary guidelines and nutritional recommendations, for both the general public and those with diet-related diseases. The result has been decades of nutritionally reductive, nutricentric guidelines and food aisles in abundance of low-fat products, which have ultimately failed to curb rates of diet-related disease. 